\title{
IMIII Differential Impact of Homelessness on Glycemic Control in Veterans with Type 2 Diabetes Mellitus
}

R. Neal Axon, MD, MSCR 1,2 , Mulugeta Gebregziabher, $P h D^{1,3}$, Clara E. Dismuke, $P h D^{1,2}$, Kelly J. Hunt, PhD 1,3, Derik Yeager, MPH', Elizabeth J. Santa Ana, PhD ${ }^{1,4}$, and Leonard E. Egede, MD, MS

${ }^{1}$ Charleston Health Equity and Rural Outreach Innovation Center, Ralph H. Johnson VA Medical Center, Charleston, SC, USA; ${ }^{2}$ Division of General Internal Medicine, Department of Medicine, The Medical University of South Carolina, Charleston, SC, USA; ${ }^{3}$ Department of Public Health Sciences, The Medical University of South Carolina, Charleston, SC, USA; ${ }^{4}$ Department of Psychiatry, The Medical University of South Carolina, Charleston, SC, USA; ${ }^{5}$ Center for Health Disparities Research Medical University of South Carolina, Charleston, SC, USA.

BACKGROUND: Veterans with evidence of homelessness have high rates of mental health and substance abuse disorders, but chronic medical conditions such as diabetes are also prevalent.

OBJECTIVE: We aimed to determine the impact of homelessness on glycemic control in patients with type 2 diabetes mellitus.

DESIGN: Longitudinal analysis of a retrospective cohort. SUBJECTS: A national cohort of 1,263,906 Veterans with type 2 diabetes. Subjects with evidence of homelessness were identified using a combination of diagnostic and administrative codes.

MAIN MEASURES: Odds for poor glycemic control using hemoglobin A1C (HbAlC) cutoff values of $8 \%$ and $9 \%$. Homeless defined as a score based on the number of indicator variables for homelessness within a veterans chart.

KEY RESULTS: Veterans with evidence of homelessness had a significantly greater annual mean $\mathrm{HbAlC} \geq 8$ (32.6\% vs. $20.43 \%$ ) and $\mathrm{HbAlC} \geq 9$ (21.4\% vs. $9.9 \%$ ), tended to be younger (58 vs. 67 years), were more likely to be non-Hispanic black (39.1\%), divorced (43\%) or never married (34\%), to be urban dwelling (88.8\%), and to have comorbid substance abuse (46.7\%), depression (42.3\%), psychoses (39.7\%), liver disease (18.8\%), and fluid/ electrolyte disorders $(20.4 \%)$, relative to non-homeless veterans (all $p<0.0001$ ). Homelessness was modeled as an ordinal variable that scored the number of times a homelessness indicator was found in the Veterans medical record. We observed a significant interaction between homelessness and race/ethnicity on the odds of poor glycemic control. Homelessness, across all racial-ethnic groups, was associated with increased odds of uncontrolled diabetes at a cut-point of $8 \%$ and $9 \%$ for hemoglobin AlC ; however, the magnitude of the association was greater in non-Hispanic whites [8\%, OR 1.55 $(1.47 ; 1.63)]$ and Hispanics [8 \%, OR $2.11(1.78 ; 2.51)]$ than in non-Hispanic blacks [8 \%, OR $1.22(1.15 ; 1.28)]$.

Electronic supplementary material The online version of this article (doi:10.1007/s11606-016-3786-z) contains supplementary material, which is available to authorized users.

Received July 23, 2015

Revised January 21, 2016

Accepted June 15, 2016

Published online July 14, 2016
CONCLUSIONS: Homelessness is a significant risk factor for uncontrolled diabetes in Veterans, especially among non-Hispanic white and Hispanic patients. While efforts to engage homeless patients in primary care services have had some success in recent years, these data suggest that broader efforts targeting management of diabetes and other chronic medical conditions remain warranted.

KEY WORDS: diabetes mellitus; homelessness; healthcare disparities; access to care; Veterans.

J Gen Intern Med 31(11): 1331-7

DOI: $10.1007 / \mathrm{s} 11606-016-3786-z$

(C) Society of General Internal Medicine 2016

\section{INTRODUCTION}

Healthcare providers and public policy officials have acknowledged that homelessness is a high-priority public health issue. ${ }^{1}$ On a given night in 2013, approximately 610,042 people were homeless in the United States, including approximately 57,849 Veterans. Thirty-three of every 10,000 Veterans experienced homelessness at least one night, and 60 of every 10,000 Veterans experienced homelessness in one year. ${ }^{2}$ Homeless individuals face many challenges in access to healthcare and managing chronic health conditions, and their age-adjusted mortality has been reported as nearly three times higher than non-homeless. ${ }^{3}$

Homelessness is associated with high rates of mental health disorders and substance abuse, but chronic health conditions are also prevalent in this population. ${ }^{4}$ In one report, $61 \%$ of homeless subjects reported having psychiatric problems and $79 \%$ reported alcohol or drug abuse or dependence. In addition, $66 \%$ of homeless subjects enrolling for medical care reported having at least one chronic medical condition. ${ }^{5}$ In another report, an estimated $38 \%$ of homeless patients had more than one chronic medical condition compared to only $27 \%$ of their peers, and over half of homeless healthcare seekers have described unmet medical needs. ${ }^{6,7}$ Homeless individuals also face a confluence of particular barriers, including competing sustenance needs, environmental stress (weather, violence, infections, trauma), and few social supports. ${ }^{8,9}$ The literature has highlighted the cumulative and 
continued impact of these risk factors even when homeless individuals achieve housing. ${ }^{7,10,11}$

Diabetes mellitus is one example of a chronic medical condition where unmet healthcare needs may impact health outcomes. Type 2 diabetes affects nearly 26 million people in the United States, or $8.3 \%$ of the U.S. population. ${ }^{12}$ Diabetes is the seventh leading cause of death and a leading cause for heart disease, stroke, kidney failure, non-traumatic lower-limb amputations, and new cases of blindness. ${ }^{12}$ Estimates for the prevalence of diabetes among homeless individuals vary somewhat but generally mirror rates in the general population, ${ }^{13-16}$ but it is clear that individuals with diabetes are more likely than non-diabetics to have mental health disorders. ${ }^{17-20}$ Wohowiak and colleagues describe over 159,000 visits to Healthcare for the Homeless clinics per year related to diabetes (19\% of all visits). ${ }^{21}$

Unfortunately, very little is currently known regarding the impact of homelessness on glycemic control in diabetes. To address this knowledge gap, we performed a longitudinal cohort study of diabetic Veterans who were identified as having either a current or past history of homelessness from the time services were delivered, hereafter referred to as having 'evidence of homelessness,' based on administrative records during the study period. We hypothesized that an evidence of homelessness among the Veteran sample would be associated with higher rates of poor diabetes control compared to Veterans without any evidence of homelessness, as measured by hemoglobin Alc values over time.

\section{METHODS}

\section{Study Population}

A national cohort of Veterans with type 2 diabetes was created by linking multiple patient and administrative files from the Veterans Health Administration (VHA) National Patient Care and Pharmacy Benefits Management databases. Veterans were included in the cohort if they had type 2 diabetes defined by two or more International Classification of Diseases, Ninth Revision (ICD-9) codes for diabetes (250, 357.2, 362.0, and 366.41 ) in the previous 24 months (2000 and 2001) and during 2002 from inpatient stays and/or outpatient visits on separate days (excluding codes from lab tests and other non-clinician visits) using a previously validated algorithm. The National Patient Care Database (NPCD) was the source data for the VHA Medical SAS data sets, which were used to analyze Veteran clinical data such as diagnosis and procedure codes for outpatient visits and inpatient admissions.

Veterans were followed from time of entry into the study until death, loss to follow-up, or through December 2010. A total of 1,263,906 qualified for the study cohort. These include $45.8 \%$ non-Hispanic white (NHW), $11 \%$ non-Hispanic black (NHB) and $2.5 \%$ Hispanic with type 2 diabetes. There were also $40.7 \%$ of Veterans with either missing or unknown race/ethnicity information. The study was approved by the
Medical University of South Carolina Institutional Review Board (IRB) and the local VA Research and Development committee.

\section{Outcome}

The outcome variable was odds of poor diabetes control as measured by annual mean hemoglobin $\mathrm{A} 1 \mathrm{C}$ values (mean $\mathrm{A} 1 \mathrm{C}>8 \%$ ) and (A1C $>9 \%$ ) over the study period for each Veteran.

\section{Primary Covariates}

The primary covariate was evidence of homelessness occurring between 2000 to 2010 based on a series of previously defined ICD-9 codes and VA clinic stop codes. ${ }^{22}$ These included ICD-9 V60.0 and V60.1 coded patients; VA homelessness stop codes 522, 530, 528, 529, 590. Stop codes as used in VA records indicate specific service types or locations. Stop code 522 and 530 involve services associated with the Housing and Urban Development Veterans Affairs Supported Housing Program, ${ }^{23}$ which combines rental assistance with case management for homeless Veterans. Stop codes 528, 529, and 590 involve services associated with Health Care for Homeless Veterans, ${ }^{24}$ (see Online Appendix Table 1 for the number of Veterans who were served by stop code and specific stop code specifiers). Homelessness was further characterized in three different ways for purposes of sensitivity analysis: (1) based on a dose-dependent score that tallied the number of homelessness indicators found in a Veterans chart, (2) as a duration dependent variable reflecting the number of years in which subjects had a homelessness indicator reflected in their medical record, and (3) homelessness indicator by year, which is a binary variable that indicates the presence of administrative and/or clinical codes for homelessness occurring within each VAMC fiscal year (October 1 to September 30) period. The indicator is defined for the fiscal year in which homelessness information is available and makes no assumptions about homelessness occurring prior to, or following, a given fiscal year. The additional models characterizing homelessness based definitions (2) and (3) are reported as sensitivity analysis in the online appendix. The second primary covariate of interest was race/ethnicity, with NHW serving as the reference group. Race/ethnicity was retrieved from the 2002 outpatient and inpatient Medical SAS data sets. When missing or unknown, the variable was supplemented using the inpatient race1-race6 fields from the 2003 Medical SAS data sets, the outpatient race1-race7 fields from the 2004 Medical SAS data sets, and the VA Vital Status Centers for Medicare and Medicaid Services (CMS) field for race.

Other potential confounders were location of residence (urban, rural or very rural), age, gender, service connected disability, marital status and comorbidities. Age was categorized into four groups $(<50$ years, 50-64, 64-74, 75 and above). Location of residence was classified as urban or rural, with highly rural being categorized as rural for homeless status 
Table 1. Subject Characteristics by Homeless Status

\begin{tabular}{|c|c|c|c|c|}
\hline characteristic & $\begin{array}{l}\text { homeless } \\
n=8,709\end{array}$ & $\begin{array}{l}\text { not } \\
\text { homeless } \\
n= \\
1,255,197\end{array}$ & $\begin{array}{l}\text { total } \\
n= \\
1,263,906\end{array}$ & $p$ \\
\hline \multicolumn{5}{|l|}{ Hemoglobin Alc } \\
\hline$\geq 8.0 \%$ & 32.65 & 20.43 & 20.52 & 0.000 \\
\hline$\geq 9.0 \%$ & 21.36 & 9.93 & 10.02 & 0.000 \\
\hline \multicolumn{5}{|l|}{ Age } \\
\hline continuous & 57.83 & 67.02 & 66.96 & 0.000 \\
\hline$\geq 65$ years $(\%)$ & 7.24 & 38.22 & 38.00 & 0.000 \\
\hline \multicolumn{5}{|l|}{ Quartiles } \\
\hline 1st quartile & 53 & 60 & 60 & \\
\hline $\begin{array}{l}\text { 2nd quartile } \\
\text { (median) }\end{array}$ & 57 & 66 & 65 & \\
\hline 3rd quartile & 62 & 76 & 76 & \\
\hline \multicolumn{5}{|l|}{ Gender $(\%)$} \\
\hline Male & 96.39 & 96.92 & 96.92 & \\
\hline Female & 3.61 & 3.08 & 3.08 & 0.005 \\
\hline \multicolumn{5}{|l|}{ Race/Ethnicity (\%) } \\
\hline NHW & 34.87 & 45.87 & 45.79 & \\
\hline NHB & 39.15 & 10.76 & 10.96 & \\
\hline Hispanic & 2.65 & 2.55 & 2.55 & \\
\hline Other & 22.95 & 40.80 & 40.67 & \\
\hline Missing & 0.38 & 0.03 & 0.03 & 0.000 \\
\hline \multicolumn{5}{|l|}{ Marital Status (\%) } \\
\hline Married & 17.03 & 65.65 & 65.31 & \\
\hline Divorced & 42.97 & 19.09 & 19.26 & \\
\hline Widowed & 3.75 & 5.26 & 5.25 & \\
\hline Never married & 34.22 & 9.46 & 9.64 & 0.000 \\
\hline \multicolumn{5}{|l|}{ Service Connected } \\
\hline $\begin{array}{l}\text { Disability }(\%) \\
\quad \geq 50 \%\end{array}$ & 12.48 & 12.84 & 12.84 & 0.374 \\
\hline \multicolumn{5}{|l|}{ Rurality (\%) } \\
\hline Urban & 88.79 & 70.78 & 70.91 & \\
\hline Rural & 8.41 & 21.64 & 21.54 & \\
\hline Super rural & 2.81 & 7.58 & 7.55 & 0.000 \\
\hline \multicolumn{5}{|l|}{ Comorbidities (\%) } \\
\hline Congestive heart & 10.22 & 10.83 & 10.82 & 0.068 \\
\hline $\begin{array}{l}\text { failure } \\
\text { Anemia }\end{array}$ & 0.91 & 0.53 & 0.54 & 0.000 \\
\hline Cancer & 7.36 & 12.49 & 12.45 & 0.000 \\
\hline Cerebrovascular & 9.31 & 6.05 & 6.07 & 0.000 \\
\hline \multicolumn{5}{|l|}{ disease } \\
\hline $\begin{array}{l}\text { Cardiovascular } \\
\text { disease }\end{array}$ & 11.73 & 16.48 & 16.44 & 0.000 \\
\hline $\begin{array}{l}\text { disease } \\
\text { Hypertension }\end{array}$ & 85.36 & 86.49 & 86.48 & 0.002 \\
\hline Hypothyroidism & 6.84 & 9.73 & 9.71 & 0.000 \\
\hline Liver disease & 18.80 & 3.82 & 3.93 & 0.000 \\
\hline Lung conditions & 1.37 & 1.14 & 1.14 & 0.043 \\
\hline \multirow{2}{*}{\multicolumn{5}{|c|}{ disorder }} \\
\hline & & & & \\
\hline Obesity & 45.54 & 40.55 & 40.59 & 0.000 \\
\hline Peripheral vascular & 10.79 & 13.64 & 13.62 & 0.000 \\
\hline \multicolumn{5}{|l|}{ disease } \\
\hline Substance abuse & 46.69 & 7.07 & 7.34 & 0.000 \\
\hline Depression & 42.26 & 20.24 & 20.39 & 0.000 \\
\hline Psychoses & 38.71 & 8.72 & 8.92 & 0.000 \\
\hline Other & 21.05 & 18.49 & 18.51 & 0.000 \\
\hline
\end{tabular}

Comorbidity definitions based on Elixhauser AHRQ-Web ICD-9-CM

reporting and collapsed to urban/rural for the logit models. Marital status was classified into four categories and collapsed to married or non-married. Service connected disability was defined as dichotomous ( $<50 \%$ versus $50 \%$ or more) serving as proxy variable to measure copay status, as has been done in multiple prior studies. ${ }^{25-27} \mathrm{We}$ also included comorbidity variables, such as congestive heart failure, anemia, cancer, cerebrovascular disease, cardiovascular disease, hypertension, hypothyroidism, liver disease, lung disease, fluid and electrolyte disorders, obesity, peripheral vascular disease, substance abuse, depression, psychoses, and others (AIDS, rheumatoid arthritis, renal failure, peptic ulcer disease and bleeding, weight loss), and these were defined based on ICD-9 codes at entry into the cohort based on previously validated algorithms. ${ }^{28}$ Comorbidities were defined as binary indicators for each comorbidity and collapsed into $0,1,2$ or 3 or more. We also created a mental health indicator variable based on the presence of any of the three mental health comorbidities (depression, substance use and psychoses).

\section{Statistical Analysis}

Univariate analyses of categorical data were performed via $t$ test and chi-squared tests. Further exploration of the trend in proportion of patients who were not in control of their diabetes was made by plotting proportion of mean $\mathrm{A} 1 \mathrm{c}>8 \%$ or mean Alc $>9 \%$ for each year by race/ethnicity. In order to explore the parameters of generalized linear models, we established a panel data set with each observation representing a unique patient-time record with time in year ranging from entry to exit from the cohort. We then fitted a logistic regression model via generalized estimating equations (GEE) accounting for the longitudinal nature of the data, using Stata's xtgee command. ${ }^{29}$ Several correlation structures were considered to capture the with-in subject correlation of outcomes, and an auto-regressive $\left[\mathrm{AR}^{1}\right]$ structure was the best fit for the model with homelessness score and duration. We used GEE with independent correlation structure and a robust standard error to fit the model for the time varying homelessness indicator, since we also included a one-time lag of the indicator to see if current homelessness was associated with current $\mathrm{A} 1 \mathrm{C}$ control after adjusting for previous homelessness. Moreover, clinically relevant variables pertaining to the study hypothesis were added and interactions were explored systematically. It was decided a priori that we would examine the differential association between homelessness and diabetes control by race/ethnicity, and hence the interaction between race/ethnicity and homelessness was assessed at $5 \%$ type I error rate. Since there was significant interaction, odds ratio estimates and their corresponding $95 \%$ confidence intervals were reported for each variable stratified by race/ethnicity. The odds ratio estimates were also depicted using forest-plot. Model diagnostics was done via residual analysis. All analysis was done in Stata $13 .{ }^{30}$

\section{RESULTS}

Subject characteristics by homeless status are reported in Table 1. Veterans with evidence of homelessness comprised $0.7 \%(8,709)$ of the total diabetes cohort. In the total diabetes cohort, $20.5 \%$ of Veterans had an annual mean $\mathrm{HbA1C} \geq 8$ and $10 \% \geq 9$. Veterans with evidence of homelessness had a significantly greater annual mean $\mathrm{HbA1C} \geq 8(32.6 \%$ vs. $20.4 \%)$ and $\mathrm{HbAlC} \geq 9(21.4 \%$ vs. $9.9 \%)$ relative to nonhomeless Veterans. The homeless cohort was significantly younger with a mean age of 58 years relative to 67 for the 
non-homeless cohort, and they were significantly more likely to be female (3.6\% vs. $3.1 \%)$. This cohort was also significantly more likely to be non-Hispanic black (39.1\% vs. $10.8 \%$ ), divorced (43\% vs. $19.1 \%$ ) and never married (34\% vs. $9.5 \%$ ). Lastly, the homeless cohort was more likely to be urban dwelling ( $88.8 \%$ vs. $70.8 \%$ ) and have higher rates of anemia ( $0.9 \%$ vs. $0.5 \%)$, cerebrovascular disease $(9.3 \%$ vs. $6 \%$ ), liver disease (18.8\% vs. $3.8 \%$ ), lung conditions $(1.4 \%$ vs. $1.1 \%)$, fluid electrolyte disorder (20.4\% vs. $11.1 \%$ ), obesity (45.5\% vs. $40.5 \%$ ), substance abuse (46.7\% vs. $7.1 \%$ ), depression (42.3\% vs. $20.2 \%$ ), and psychoses $(38.7 \%$ vs. $8.7 \%)$.

From the logit models for $\mathrm{HbA1C}>8$ and $\mathrm{HbA1C}>9$ stratified by race, the adjusted odds ratios and $95 \%$ CIs for the homeless dose-dependent score and covariates are shown in Table 2. Homelessness was modeled as an ordinal variable that scored the number of times a homelessness indicator was found in the veteran's medical record. We observed a significant interaction between homelessness and race/ethnicity on the odds of poor glycemic control. Homelessness, across all racial-ethnic groups, was associated with increased odds of uncontrolled diabetes at a cut-point of $8 \%$ and a cut-point of $9 \%$ for hemoglobin A1C; however, the magnitude of the association was greater in nonHispanic whites [8 \%, OR $1.55(1.47 ; 1.63)$ ], Hispanics [8\%, OR $2.11(1.78 ; 2.51)]$ and the Other/missing raceethnicity group [8\%, OR $1.57(1.51 ; 1.63)]$ than in nonHispanic blacks [8 \%, OR $1.22(1.15 ; 1.28)]$. Results remained significant and followed a similar pattern when a $\mathrm{HbAlc}$ cut-point of $>9.0 \%$ was utilized. Figure 1 shows a forest plot of these odds ratios and $95 \%$ CI of the association of HbAlc with race/ethnicity. We also modeled homelessness as a duration-dependent variable reflecting the number of years in which subjects had a homelessness indicator reflected in their medical record and as time varying covariate with one time lag. Online Supplementary Figures $2 \mathrm{a}$ and $2 \mathrm{~b}$ show the trend of the proportion of people with poor A1c control over time for the overall and stratified by race respectively. Overall, those with indications of homelessness had a higher likelihood of poor glycemic control. However, the trend for both the homeless and not homeless seems to decrease slightly over time. The analysis results for the additional homelessness variables are reported in Online Supplementary Tables 2a, 2b and 2c. While the results in Table 2a are consistent with the primary results reported in Table 2 , the results in Table $2 \mathrm{~b}$ $(\mathrm{A} 1 \mathrm{c}>8)$ and $2 \mathrm{c}(\mathrm{A} 1 \mathrm{c}>9)$ are slightly different. In the unadjusted analysis, both previous homelessness and current homelessness were associated with current A1c control. However, when we adjusted for covariates, the association between current A1c and previous homelessness became statistically nonsignificant. Thus, we excluded previous homelessness from our final model and this resulted in nonsignificant associations for NHB and Hispanic groups. This could be due to the limitations of the time varying homelessness indicator measurement.

We present the dose dependent results as our primary analysis, because these models explained a higher proportion of the variability observed in hemoglobin A1c than did the duration-dependent homelessness models.

Table 2. Adjusted ORs for homelessness (Score) and $95 \%$ CIs by race and HbA1c level

\begin{tabular}{|c|c|c|c|c|c|}
\hline Variable & Value & NHW & NHB & Hispanic & Other \\
\hline \multicolumn{6}{|l|}{ HbAlc levels $>8.0 \%$} \\
\hline Homelessness & \# of indicators & $1.55(1.47 ; 1.63)$ & $1.22(1.15 ; 1.28)$ & $2.11(1.78 ; 2.51)$ & $1.57(1.51 ; 1.63)$ \\
\hline Age & Centered & $0.97(0.97 ; 0.97)$ & $0.98(0.98 ; 0.98)$ & $0.97(0.97 ; 0.97)$ & $0.96(0.96 ; 0.96)$ \\
\hline Gender & Female & $0.78(0.76 ; 0.79)$ & $0.74(0.71 ; 0.74)$ & $0.79(0.72 ; 0.87)$ & $0.76(0.74 ; 0.77)$ \\
\hline Marital Status & Married & $0.89(0.89 ; 0.90)$ & $0.94(0.93 ; 0.96)$ & $0.98(0.96 ; 1.01)^{\mathrm{NS}}$ & $0.89(0.88 ; 0.90)$ \\
\hline Service Connected & Yes $\geq 50 \%$ & $0.79(0.78 ; 0.80)$ & $0.73(0.72 ; 0.74)$ & $0.64(0.61 ; 0.66)$ & $0.71(0.70 ; 0.71)$ \\
\hline Rurality Status & Urban & $0.99(0.98 ; 0.99)^{* *}$ & $1.01(0.99 ; 1.03)^{\mathrm{NS}}$ & $1.16(1.12 ; 1.20)$ & $1.05(1.04 ; 1.06)$ \\
\hline \multirow[t]{4}{*}{ Comorbidity } & 1 (referent 0 ) & $1.43(1.40 ; 1.47)$ & $1.53(1.47 ; 1.59)$ & $1.34(1.20 ; 1.49)$ & $1.48(1.45 ; 1.51)$ \\
\hline & 2 & $1.93(1.89 ; 1.98)$ & $2.00(1.93 ; 2.08)$ & $1.80(1.62 ; 1.99)$ & $1.93(1.88 ; 1.97)$ \\
\hline & 3 or more & $2.91(2.85 ; 2.98)$ & $2.96(2.84 ; 3.07)$ & $2.45(2.21 ; 2.73)$ & $2.74(2.68 ; 2.81)$ \\
\hline & Mental Health & $1.05(1.04: 1.06)$ & $1.03(1.02 ; 1.05)$ & $1.00(0.97 ; 1.03)^{\mathrm{NS}}$ & $1.01(1.01 ; 1.02)$ \\
\hline Study Year & Centered & $1.34(1.33 ; 1.36)$ & $1.26(1.24 ; 1.28)$ & $1.18(1.14 ; 1.22)$ & $1.45(1.44 ; 1.46)$ \\
\hline \multicolumn{6}{|l|}{ HbAlc levels $>9.0 \%$} \\
\hline Homelessness & \# of indicators & $1.73(1.61 ; 1.85)$ & $1.13(1.07 ; 1.22)$ & $2.08(1.70 ; 2.53)$ & $1.87(1.78 ; 1.97)$ \\
\hline Age & Centered & $0.94(0.94 ; 0.94)$ & $0.95(0.95 ; 0.95)$ & $0.96(0.95 ; 0.96)$ & $0.94(0.94 ; 0.94)$ \\
\hline Gender & Female & $0.68(0.66 ; 0.70)$ & $0.62(0.60 ; 0.65)$ & $0.70(0.62 ; 0.79)$ & $0.69(0.67 ; 0.71)$ \\
\hline Marital Status & Married & $0.86(0.85 ; 0.87)$ & $0.95(0.93 ; 0.96)$ & $0.88(0.84 ; 0.91)$ & $0.80(0.79 ; 0.81)$ \\
\hline Service Connected & Yes $\geq 50 \%$ & $0.62(0.61 ; 0.63)$ & $0.56(0.54 ; 0.57)$ & $0.61(0.58 ; 0.64)$ & $0.67(0.66 ; 0.68)$ \\
\hline Rurality Status & Urban & $1.04(1.03 ; 1.06)$ & $1.03(1.01 ; 1.06)^{* *}$ & $1.10(1.04 ; 1.15)$ & $1.11(1.10 ; 1.12)$ \\
\hline \multirow{4}{*}{ Comorbidity } & 1 (referent 0$)$ & $1.19(1.15 ; 1.23)$ & $1.23(1.17 ; 1.29)$ & $1.04(0.90 ; 1.20)^{\mathrm{NS}}$ & $1.22(1.18 ; 1.26)$ \\
\hline & 2 & $1.39(1.35 ; 1.43)$ & $1.35(1.29 ; 1.42)$ & $1.30(1.13 ; 1.49)$ & $1.40(1.35 ; 1.44)$ \\
\hline & 3 or more & $1.82(1.76 ; 1.87)$ & $1.71(1.63 ; 1.80)$ & $1.70(1.48 ; 1.95)$ & $1.83(1.77 ; 1.88)$ \\
\hline & Mental Health & $1.02(1.01 ; 1.04)$ & $1.01(0.99 ; 1.03)^{\mathrm{NS}}$ & $1.06(1.01 ; 1.10)^{* *}$ & $1.03(1.02 ; 1.04)$ \\
\hline Study Year & Centered & $1.15(1.13 ; 1.17)$ & $1.13(1.11 ; 1.16)$ & $1.06(1.02 ; 1.11)$ & $1.04(1.03 ; 1.06)$ \\
\hline
\end{tabular}

NHW $=$ Non-Hispanic White NHB $=$ Non-Hispanic Black

$p<0.001$ for all tests unless otherwise noted. $*=p<0.05 ; * *=p<0.01 ;$ Not statistically significant $=$ NS;

Study year (quadratic) was not statistically significant; $p>0.05$

Race by homelessness interaction was statistically significant, $p<0.01$ 


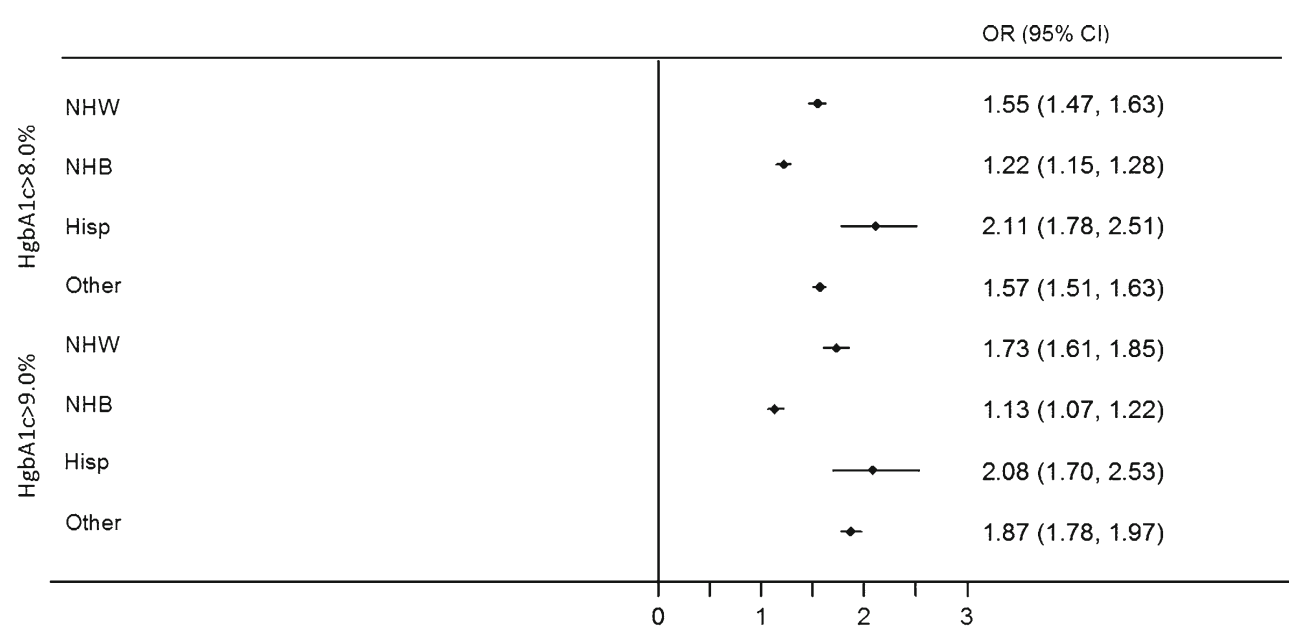

Figure 1. Forest plot of ORs and $95 \%$ CIs of homelessness (score) by race and HgbA1c threshold.

\section{DISCUSSION}

In this study, we report longitudinal diabetes control outcomes for patients with evidence of homelessness. We observed a significant interaction between homelessness and race/ethnicity such that evidence of homelessness was associated with more pronounced effects on hemoglobin $\mathrm{A} 1 \mathrm{C}$ in non-Hispanic whites as compared to non-Hispanic blacks and Hispanic subjects. To our knowledge, this finding has not been reported in prior literature. Specifically, in stratified analyses, across all race-ethnic groups, each indicator of homelessness was associated with increased odds of uncontrolled and poorly controlled diabetes. The association was strongest in Hispanics with odds ratios of 2.11 and 2.08, respectively, for HbAlc cut-points of $8 \%$ and $9 \%$; and weakest in nonHispanic blacks with respective odds ratios of 1.22 and 1.13 . While relative associations for glycemic control with homelessness are weakest in non-Hispanic blacks, it is important to remember that these subjects had the highest overall levels of poor diabetes control at baseline and over time. These results confirm our hypothesis that homelessness is associated with poor diabetes control.

Very few studies have examined the impact of homelessness per say on diabetes outcomes, although studies have reported on associations between glycemic control and constructs related to homelessness including material need insecurity and food insecurity. ${ }^{31-33}$ Randall and colleagues found that homelessness was a significant risk factor for repeated hospitalization for diabetic ketoacidosis. ${ }^{34}$ Twenty-three $\%$ of patients with recurrent DKA had a history of homelessness in this study conducted in an urban safety-net hospital. It is clear that homelessness presents multiple challenges, some of which include: limited and variable access to food; difficulty in acquiring and storing diabetes medications, especially insulin; high levels of physical and psychological stress; and difficulty in accessing primary and specialty care with continuity over time. ${ }^{21}$ For these reasons, the Health Care for the Homeless Clinicians Network has developed guidelines to enable providers to address the unique challenges of caring for homeless diabetic patients. ${ }^{35}$ This monograph references current standards for the care of diabetes while offering practical suggestions, such as avoiding sulfonylureas, which might cause hypoglycemia in patients with inconsistent food supplies.

Maslow's hierarchy of needs would suggest that addressing basic physiologic and safety needs might be an important approach to improving glycemic control among homeless diabetic patients. ${ }^{36}$ A number of innovative programs have been developed to speed the process of finding stable housing, yet these efforts are often hampered by ongoing social, psychological, and substance abuse problems among enrollees. Nevertheless, Collins and colleagues describe the success of a Housing First program, which enrolled 111 chronically homeless individuals with severe alcohol use problems. ${ }^{37}$ At 2-year follow-up, only $23 \%$ of participants had returned to homelessness. The Department of Veterans Affairs has also had success with its housing first initiative tailored for Veterans, the Housing and Urban Development VA Supportive Housing program (HUD-VASH). ${ }^{38}$

Prior literature suggests that once stable housing is established, enrollment in primary and specialty care appears to be important to optimize outcomes and reduce unnecessary healthcare utilization among homeless patients. Multiple prior studies have documented extensive use of emergency department and inpatient care by homeless individuals. ${ }^{39-42}$ For example, Tsai and colleagues found that homeless Veterans had four times the odds of using EDs than non-homeless Veterans. ${ }^{40}$ However, Gabrielian and colleagues noted that while HUD-VASH enrolled Veterans had initial significant increases in primary care and specialty utilization upon enrollment, HUD-VASH Veterans and low-income housed Veterans had similar likelihoods of medical/surgical inpatient and outpatient utilization compared with non-homeless peers over time. ${ }^{38}$ Enrollees also had significant decreases in incidence rates of ED care after adjusting for demographics and need in addition to primary care usage. O'Toole and colleagues (2010) 
also report reductions in risk for emergency department and inpatient usage among homeless Veterans with higher levels of primary care engagement. ${ }^{4}$

This analysis should be interpreted in light of certain limitations. First, we analyzed a retrospective cohort of Veterans with type 2 diabetes mellitus using diagnostic and administrative codes to identify subjects at high likelihood for having had an episode of homelessness. These codes do not necessarily equate to prospectively validated episodes of homelessness, and were limited in that it was not possible to define temporally when the homelessness episodes occurred with confidence. Nevertheless, these diagnostic and administrative codes have been used in prior studies, and subjects identified as having evidence of homelessness in this study had characteristics (e.g., age, mental health disorders, and substance abuse) consistent with homeless populations in other cohorts. A related concern is that our primary measure of homelessness is not time varying (even though we did sensitivity analysis with time varying form that has been measured in a limited way), and our analysis focused on a 10-year period. Thus, we cannot make inferences about the variation in glycemic control corresponding to individual instances of homelessness. Hence, interpretation of results is limited in that it is not clear whether homelessness itself or longer-standing conditions that predispose to homelessness are associated with poor glycemic control over a 10-year period. Future studies should examine variations in glycemic control among this population while cross-referencing data describing patient homelessness status, length of time homeless, type of residence or shelter and number of times shelter was sought, among other homelessness indicators. Second, our cohort was overwhelmingly male, so our results may not be generalizable to non-Veteran female populations. Finally, though all subjects were enrolled in VA primary care, we were unable to measure the frequency of primary care visits in this study. It is possible that adjustment for the intensity of primary care might have attenuated our observed effect sizes.

In summary, our results suggest that homelessness is a significant risk factor for uncontrolled diabetes across all racial-ethnic groups. ${ }^{43}$ The U.S Department of Veterans Affairs and other governmental organizations have made significant commitments toward ending homeless. ${ }^{44}$ Fortunately, recent reports document that homelessness is diminishing nationwide. In the current study, our homeless cohort exhibited suboptimal diabetes control despite that a significant proportion of the cohort were receiving VA housing Services (i.e., HUD-VASH, HCHV). More studies are needed to evaluate the impact of innovative programs and novel approaches that may positively impact chronic medical issues that homeless Veterans continue to face once they achieve residential or permanent housing. Three areas of research that may supplement integrated medical home models are: self-management approaches delivered in the patient's residence, such as those utilizing care coordination home telehealth (CCHT) for chronic disease management ${ }^{45}$; identifying risk and need profiles of homeless patients that may be utilized for matching needed medical services and specialized services for addressing disabling medical conditions ${ }^{46}$; and studies that evaluate broader social determinants including location, or the neighborhood community, within which homeless Veterans are provided with supported housing, including neighborhood access to affordable and healthy foods and availability of safe recreational areas for physical activity. ${ }^{10}$

\section{Acknowledgements:}

1. This study was supported by grant \#IIR-06-219 funded by the VHA Health Services Research and Development (HSR\&D) program (PI: Leonard Egede). The funding agency did not participate in the design and conduct of the study; collection, management, analysis, and interpretation of the data; and preparation, review, or approval of the manuscript. The manuscript represents the views of the authors and not those of the VA or HSR\&D.

2. Drs. Leonard E Egede and Mulugeta Gebregziabher are the guarantors of this work, and, as such, had full access to all the data in the study and take responsibility for the integrity of the data and the accuracy of the data analysis.

3. This work has not previously been presented.

Authors' Contributions: Study concept and design: Egede, Gebregziabher, Axon

Acquisition of data: Egede

Analysis and interpretation of data: Gebregziabher, Hunt, Yeager, Egede

Drafting of the manuscript: Axon, Gebregziabher, Hunt, Dismuke, Yeager, Santa Ana, Egede

Critical revision of the manuscript for important intellectual content: Axon, Gebregziabher, Hunt, Dismuke, Yeager, Santa Ana, Egede

Final approval of manuscript: Axon, Gebregziabher, Hunt, Dismuke, Yeager, Santa Ana, Egede

Corresponding Author: Leonard E. Egede, MD, MS; Center for Health Disparities Research Medical University of South Carolina, 135 Rutledge Avenue, MSC 593, Charleston, SC 29425-0593, USA (e-mail: egedel@musc.edu).

\section{Compliance with Ethical Standards:}

Conflict of Interest: The authors declare that they do not have a conflict of interest.

\section{REFERENCES}

1. Donovan S, Shinseki EK. Homelessness is a public health issue. Am J Public Health. 2013;103(Suppl 2):S180. doi:10.2105/ajph.2013.301727.

2. Balshem H, Christensen V, Tuepker A, Kansagara D. A Critical Review of the Literature Regarding Homelessness Among Veterans. Washington DC2011.

3. O'Toole TP, Bourgault C, Johnson EE, Redihan SG, Borgia M, Aiello R, et al. New to care: demands on a health system when homeless veterans are enrolled in a medical home model. Am J Public Health. 2013;103(Suppl 2):S374-9. doi:10.2105/ajph.2013.301632.

4. O'Toole TP, Buckel L, Bourgault C, Blumen J, Redihan SG, Jiang L, et al. Applying the chronic care model to homeless veterans: effect of a population approach to primary care on utilization and clinical outcomes. Am J Public Health. 2010;100(12):2493-9. doi:10.2105/ajph.2009. 179416.

5. Balshem H, Christensen V, Tuepker A, Kansagara D. A Critical Review of the Literature Regarding Homelessness among Veterans: VA-ESP Project \#05-2252011.

6. Homelessness and health: What's the connection" Fact Sheet. National Health Care for the Homeless Council. Accessed at http://www.nhchc.org/ wp-content/uploads/2011/09/Hln_health_factsheet_Jan10.pdf on June 2, 2016

7. Kertesz SG, McNeil W, Cash JJ, Desmond R, McGwin G Jr, Kelly J, et al. Unmet need for medical care and safety net accessibility among 
Birmingham's homeless. J Urban Health. 2014;91(1):33-45. doi:10.1007/ s11524-013-9801-3.

8. Gelberg L, Gallagher TC, Andersen RM, Koegel P. Competing priorities as a barrier to medical care among homeless adults in Los Angeles. Am J Public Health. 1997;87(2):217-20.

9. Epel ES. Psychological and metabolic stress: a recipe for accelerated cellular aging? Hormones (Athens, Greece). 2009;8(1):7-22.

10. Henwood BF, Cabassa LJ, Craig CM, Padgett DK. Permanent supportive housing: addressing homelessness and health disparities? Am J Public Health. 2013;103(Suppl 2):S188-92. doi:10.2105/ajph.2013.301490.

11. Baggett TP, Hwang SW, O'Connell JJ, Porneala BC, Stringfellow EJ, Orav EJ, et al. Mortality among homeless adults in Boston: shifts in causes of death over a 15-year period. JAMA Int Med. 2013;173(3): 189-95. doi:10.1001/jamainternmed.2013.1604.

12. Prevention CfDCa. National diabetes fact sheet: national estimates and general information on diabetes and prediabetes in the United States, 2011..In: U.S. Department of Health and Human Services CfDCaP, editor. Atlanta, GA: 2011 .

13. Arnaud A, Fagot-Campagna A, Reach G, Basin C, Laporte A. Prevalence and characteristics of diabetes among homeless people attending shelters in Paris, France, 2006. Eur J Pub Health. 2010;20(5):601-3. doi:10.1093/ eurpub/ckp197.

14. Scott J, Gavin J, Egan AM, Avalos G, Dennedy MC, Bell M, et al. The prevalence of diabetes, pre-diabetes and the metabolic syndrome in an Irish regional homeless population. QJM. 2013;106(6):547-53. doi:10. 1093/qjmed/hct063.

15. Notaro SJ, Khan M, Kim C, Nasaruddin M, Desai K. Analysis of the health status of the homeless clients utilizing a free clinic. J Community Health. 2013;38(1):172-7. doi:10.1007/s10900-012-9598-0.

16. Lee TC, Hanlon JG, Ben-David J, Booth GL, Cantor WJ, Connelly PW, et al. Risk factors for cardiovascular disease in homeless adults. Circulation. 2005;111(20):2629-35. doi:10.1161/circulationaha.104.510826.

17. Egede LE, Ellis C. Diabetes and depression: global perspectives. Diabetes Res Clin Pract. 2010;87(3):302-12. doi:10.1016/j.diabres.2010.01.024.

18. Dickerson F, Brown CH, Fang L, Goldberg RW, Kreyenbuhl J, Wohlheiter $\mathbf{K}$, et al. Quality of life in individuals with serious mental illness and type 2 diabetes. Psychosomatics. 2008;49(2):109-14. doi:10. 1176/appi.psy.49.2.109.

19. Fisher L, Skaff MM, Mullan JT, Arean P, Glasgow R, Masharani U. A longitudinal study of affective and anxiety disorders, depressive affect and diabetes distress in adults with Type 2 diabetes. Diabet Med. 2008;25(9):1096-101. doi:10.1111/j.1464-5491.2008.02533.x.

20. Hultsjo SM, Hjelm K. Organizing care for persons with psychotic disorders and risk of or existing diabetes mellitus type 2. J Psychiatr Ment Health Nurs. 2012;19(10):891-902. doi:10.1111/j.1365-2850.2012.01874.x.

21. Wahowiak L. On the streets. How do you manage your diabetes when you're worried about finding your next meal? Diabetes forecast. 2012;65(12):48-51.

22. Hastings SN, Smith VA, Weinberger M, Oddone EZ, Olsen MK, Schmader KE. Health services use of older veterans treated and released from veterans affairs medical center emergency departments. J Am Geriatr Soc. 2013;61(9):1515-21. doi:10.1111/jgs. 12417.

23. US Department of Veterans Affairs. Department of Housing and Urban Development-Department of Veterans Affairs Supported Housing program (HUD-VASH). West Haven, CT: Northeast Program Evaluation Center: 2010.

24. US Department of Veterans Affairs. Health Care for Homeless Veterans Programs: Twenty-fourth Annual Report. West Haven, CT: Northeast Program Evaluation Center; 2011.

25. Axon RN, Gebregziabher M, Echols C, Gilbert GE, Egede LE. Racial and Ethnic Differences in Longitudinal Blood Pressure Control in Veterans with Type 2 Diabetes Mellitus. J Gen Intern Med. 2011. In Press.

26. Egede LE, Gebregziabher M, Hunt KJ, Axon RN, Echols C, Gilbert GE, et al. Regional, geographic, and racial/ethnic variation in glycemic control in a national sample of veterans with diabetes. Diabetes Care. 2011;34(4):938-43. doi:10.2337/dc10-1504.

27. Egede LE, Gebregziabher M, Hunt KJ, Axon RN, Echols C, Gilbert GE, et al. Regional, Geographic, and Ethnic Differences in Medication Adherence Among Adults with Type 2 Diabetes (February). Ann Pharmacother. 2011. doi:10.1345/aph.1P442.
28. Guan H, Sundararajan V, Halfon P, Fong A, Burnand B, Luthi J-C, et al. Coding algorithms for defining comorbidities in ICD-9-CM and ICD-10 administrative data. Med Care. 2005;43(11):1130-9.

29. Fitzmaurice GM, Laird NM, Ware JH. Applied longitudinal analysis Hoboken, N.J: Wiley-Interscience; 2004.

30. StataCorp. Stata Statistical Software: Release 12. College Station, TX: StataCorp LP; 2011.

31. Berkowitz SA, Gao $\mathbf{X}$, Tucker $\mathbf{K L}$. Food-insecure dietary patterns are associated with poor longitudinal glycemic control in diabetes: results from the Boston Puerto Rican Health study. Diabetes Care. 2014;37(9):2587-92. doi: 10.2337/dc14-0753.

32. Berkowitz SA, Meigs JB, DeWalt D, Seligman HK, Barnard LS, Bright OJ, et al. Material need insecurities, control of diabetes mellitus, and use of health care resources: results of the Measuring Economic Insecurity in Diabetes study. JAMA internal medicine. 2015;175(2):257-65. doi:10. 1001/jamainternmed.2014.6888.

33. Wang EA, McGinnis KA, Goulet J, Bryant K, Gibert C, Leaf DA, et al. Food insecurity and health: data from the Veterans Aging Cohort Study. Public Health Rep. 2015;130(3):261-8.

34. Randall L, Begovic J, Hudson M, Smiley D, Peng L, Pitre N, et al. Recurrent diabetic ketoacidosis in inner-city minority patients: behavioral, socioeconomic, and psychosocial factors. Diabetes Care. 2011;34(9):18916. doi:10.2337/dc11-0701.

35. Kalinowski A, Tinker T, Wismer B, Meinbresse M. Adapting Your Practice: Treatment and Recommendations for People Who Are Homeless with Diabetes Mellitus. Health Care for the Homeless Clinicians' Network: Nashville; 2013.

36. Maslow AH. A theory of human motivation. Psychol Rev. 1943;50(4):370-96.

37. Collins SE, Malone DK, Clifasefi SL. Housing retention in single-site housing first for chronically homeless individuals with severe alcohol problems. Am J Public Health. 2013;103(Suppl 2):S269-74. doi:10.2105/ ajph.2013.301312.

38. Gabrielian S, Yuan AH, Andersen RM, Rubenstein LV, Gelberg L. VA Health Service Utilization for Homeless and Low-income Veterans: A Spotlight on the VA Supportive Housing (VASH) Program in Greater Los Angeles. Med Care. 2014;52(5):454-61. doi:10.1097/mlr.0000000000000112.

39. O'Toole TP, Conde-Martel A, Gibbon JL, Hanusa BH, Fine MJ. Health care of homeless veterans. J Gen Intern Med. 2003;18(11):929-33.

40. Tsai J, Doran KM, Rosenheck RA. When health insurance is not a factor: national comparison of homeless and nonhomeless US veterans who use Veterans Affairs Emergency Departments. Am J Public Health. 2013;103(Suppl 2):S225-31. doi:10.2105/ajph.2013.301307.

41. Doran KM, Vashi AA, Platis S, Curry LA, Rowe M, Gang M, et al. Navigating the boundaries of emergency department care: addressing the medical and social needs of patients who are homeless. Am J Public Health. 2013;103(Suppl 2):S355-60. doi:10.2105/ajph.2013.301540.

42. Doran KM, Raven MC, Rosenheck RA. What drives frequent emergency department use in an integrated health system? National data from the Veterans Health Administration. Ann Emerg Med. 2013;62(2):151-9. doi:10.1016/j.annemergmed.2013.02.016.

43. Department of Veterans Affairs FY 2014-2020 Strategic Plan.accessed online at http://www.va.gov/op3/docs/strategicplanning/va20142020strategicplan.pdf on June 2, 2016.

44. Gabrielian S, Yuan A, Andersen RM, McGuire J, Rubenstein L, Sapir N, et al. Chronic disease management for recently homeless veterans: a clinical practice improvement program to apply home telehealth technology to a vulnerable population. Med Care. 2013;51(3 Suppl 1):S44-51. doi:10. 1097/MLR.0b013e31827808f6.

45. Tsai AC, Karasic DH, Hammer GP, Charlebois ED, Ragland K, Moss AR, et al. Directly observed antidepressant medication treatment and HIV outcomes among homeless and marginally housed HIV-positive adults: a randomized controlled trial. Am J Public Health. 2013;103(2):308-15. doi:10.2105/ajph.2011.300422.

46. The 2013 Annual Homeless Assessment Report (AHAR) to Congress: Part 1.:The U.S. Department of Housing and Urban Development Office of Community Planning and Development accessed online at https://www. onecpd.info/resources/documents/AHAR-2013-Part1.pdf on June 2, 2016 